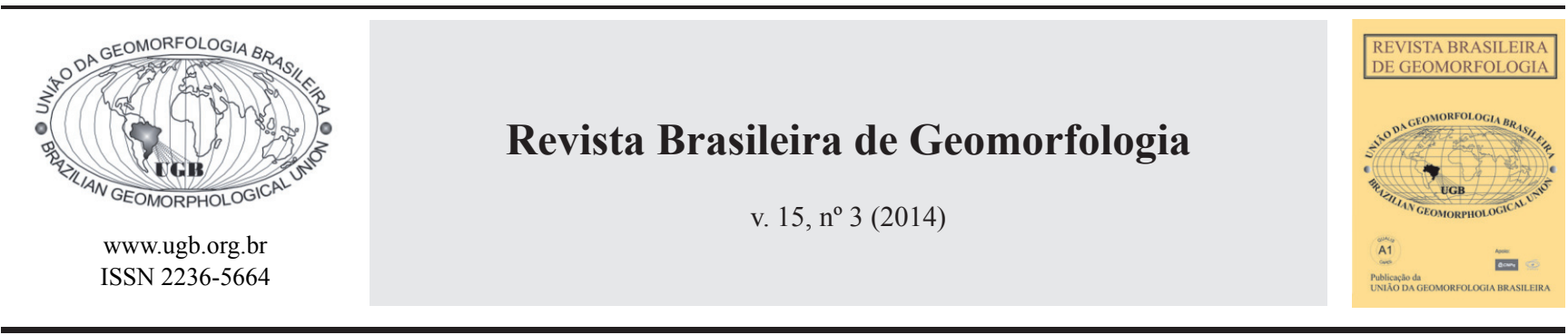

\title{
PERDA DE SOLO EM CULTIVO DE TABACO SOB DIFERENTES FORMAS DE CULTIVO NA REGIÃO SUDESTE DO PARANÁ
}

\section{SOIL LOSS IN TOBACCO CULTIVATION ON DIFFERENT TILLAGE SYSTEM IN THE SOUTHEASTERN OF PARANA}

\author{
Valdemir Antoneli \\ Departamento de Geografia, Universidade Estadual do Centro-Oeste. \\ Campus de Irati, Rodovia PR-153, km 7, Riozinho, Irati/PR, Cep: 84500-000, Brasil. \\ E-mail:vaantoneli@gmail.com \\ Edivaldo Lopes Thomaz \\ Departamento de Geografia, Universidade Estadual do Centro-Oeste. \\ Campus CEDETEG, Rua Simeão Camargo Varela de Sá, 03, Vila Carli, Guarapuava/PR, Cep: 85040-080, Brasil. \\ E-mail: thomaz@unicentro.br
}

\section{Informações sobre o Artigo}

Data de Recebimento:

21/04/2014

Data de Aprovação:

$29 / 07 / 2014$

\section{Palavras-chave:}

Erosão do solo; Fumicultura;

Plantio Direto; Plantio

Convencional.

\section{Keywords:}

Soil erosion; Tobacco cultivation; No-till;

Conventional tillage.

\section{Resumo:}

O cultivo do tabaco na região Sudeste do Estado do Paraná é realizado em pequenas propriedades absorvendo grande parte da mão-de-obra familiar. As áreas de cultivo geralmente possuem restrições ao uso por apresentarem solos rasos e declividade superior a $20 \%$, o que condiciona a utilização do plantio convencional com a utilização da tração animal. De forma incipiente está sendo adotado o plantio direto nas áreas que permitem o uso de implementos agrícolas. No plantio convencional, o solo fica exposto, sendo revolvido constantemente desde o plantio do tabaco (em setembro) até o início da colheita (em dezembro). Já no plantio direto há uma redução das atividades de revolvimento do solo devido à camada morta. A variação das atividades de manejo pode promover respostas hidrológicas e geomorfológicas diferentes nas duas formas de cultivo. Para identificar tais respostas este trabalho se propôs a avaliar a exposição do solo, compactação, infiltração perda de água e solo nos dois tipos de cultivo ao longo da safra de 2009/2010. Foram estudadas duas áreas em uma mesma vertente com diferentes formas de cultivo. O monitoramento teve inicio no mês de setembro (plantio) a março (término da colheita). Ao término da pesquisa observou-se que a infiltração média de água no solo no plantio direto foi $20,9 \%$ superior ao plantio convencional e a compactação do solo foi 78,4\% superior no plantio convencional. Já a perda de água por escoamento no plantio direto foi 3 vezes inferior ao plantio convencional e a perda de solo foi 6 vezes maior no plantio convencional. 


\begin{abstract}
:
The plantation of tobacco in the southeastern area of Parana state is performed on small farms absorbing much of the family hand labor. Growing areas often have restrictions to its use for presenting shallow soils and slopes higher than $20 \%$, which constrains the use of conventional planting with the use of animal traction for performing the activities. A direct planting is being adopted incipiently in areas where the use of agricultural implements is allowed. In conventional planting the soil is exposed, thus being constantly upturned from tobacco planting (in September) until the harvest begins (in December). In direct planting there is a reduction in soil disturbance activities due to the dead layer. The range of handling activities can promote different hydrological and geomorphological responses in both forms of cultivation. To identify such responses, this study proposes to evaluate soil exposure, compaction, infiltration, water and soil loss in both types of cultivation throughout the 2009/2010 harvest. Two areas in the same point with different forms of cultivation were studied. The monitoring began in September (planting) to March (the end of the harvest). At the end of the study it was observed that the average water infiltration in soil in direct planting was $20.9 \%$ higher than in conventional planting and soil compaction was $78.4 \%$ higher than in conventional planting. The loss of water by flowing in direct planting was 3 times lower than in conventional planting and the soil loss was 6 times higher in conventional planting.
\end{abstract}

\section{Introdução}

Nas últimas décadas o cultivo do tabaco vem se intensificando na Região Sudeste do Estado do Paraná, devido a alguns fatores como a internacionalização das empresas fumageiras, inserção de multinacionais, abertura de novos mercados internacionais, inserção de tecnologia nas fases do cultivo, além de novos métodos e técnicas de cultivo. Isso fez com que áreas com certas restrições morfopedológicas (solos rasos e declividade superior a $20 \%$ ), passassem a ser agricultáveis. A utilização dessas áreas para o cultivo do tabaco acaba potencializando as perdas de solo, principalmente por ser cultivado na forma de Plantio Convencional (exposição e revolvimento constante do solo), sem a aplicação de técnicas conservacionistas como o plantio direto e plantio em curva de nível.

A não utilização dessas técnicas potencializa a degradação dos solos em áreas de cultivo de tabaco, indicando perda de solo acima da tolerância em áreas cultiváveis (WOOD \& WORSHAM, 1986; SLATTERY 1997, ANTONELI, 2011), levando a degradação dos recursos naturais (MERTEN \& MINELLA 2006; PELEGRINI, 2006).

A utilização das áreas com restrições ao uso, em muitos casos é por falta de opção de terrenos mais adequados, pois as propriedades são constituídas por pequenas glebas de terra, dificultando assim a utilização de práticas conservacionistas. A transformação dessas áreas com restrições em áreas agricultáveis ao longo do tempo tem promovido o agravamento da degradação dos solos (BARTON et al., 2004) podendo levar ao abandono das terras cultiváveis devido a redução da produtividade (BAKKER et al., 2005).

Diversas pesquisas encontradas na literatura comparam as perdas de água e solo em áreas de Plantio Convencional (PC) e Plantio Direto (PD), no intuito de identificar a eficiência do Plantio Direto na redução de perdas de solo, bem como avaliar a degradação dos solos com Plantio Convencional (LANGDALE et al., 1979; LAL, 1993; OWENS et al., 2002; SCHULLER et al., 2007; JEMAI et al., 2013).

Pesquisas acerca da erosão de solo em cultivo de tabaco com Plantio Convencional e Plantio Direto são restritas, pois o Plantio Direto é uma técnica pouco aplicada neste tipo de cultura agrícola, devido às restrições ao uso de implementos agrícolas uma vez que ela é comum em pequena propriedade com utilização de mão-de-obra familiar.

Para o plantio do tabaco (Nicotiana tabacun) é necessário construir camalhões, com certa declividade para que a água seja escoada do interior da lavoura para as bordas. A construção desses camalhões auxilia na redução da saturação de água no solo que é prejudicial ao desenvolvimento da planta. Esses camalhões são construídos com cerca de 1,5 metros de distância um do outro formando as entrelinhas por onde os agricultores transitam ao longo do cultivo. O comprimento desses camalhões varia de acordo com o terreno, mas geralmente abrange toda a extensão da área cultivada.

Cabe considerar, que os camalhões são construídos 
através da utilização de um implemento rudimentar de tração animal ou com uso de implementos agrícolas em áreas menos declivosas (inferior a 15\%). Através da utilização destes equipamentos, o solo é agrupado, formando um "amontoado" linear de aproximadamente $40 \mathrm{~cm}$ de altura, onde será efetuado o plantio do tabaco.

As entrelinhas que se formam entre os camalhões na preparação do solo para o plantio do tabaco tornam-se carreadores (caminhos) para os agricultores ao longo do cultivo, além de comportarem-se como canais efêmeros promovendo fluxos longos, o que pode gerar uma grande quantidade de escoamento superficial e erosão, mesmo em terreno plano (SLATTERY et al.,1997).

Entre as duas formas de cultivo (PC e PD) na fumicultura há variação nas atividades de manejo durante as fases do cultivo alterando a exposição do solo, compactação, infiltração o que influencia diretamente nas perdas de água e solo. Diante do exposto, esta pesquisa se propôs a avaliar a perda de água e solo em uma área de cultivo de tabaco com Plantio Convencional e Plantio Direto, no intuito de identificar a eficiência do Plantio Direto na redução das perdas de água e solo ao longo de uma safra (2009/2010). A pesquisa foi realizada em uma propriedade rural localizada na Bacia do Arroio Boa Vista Município de Guamiranga-PR. A perda de água e solo foi correlacionada com a variabilidade na exposição do solo, compactação e infiltração.

\section{Caracterização da área de estudos}

A Bacia do Arroio Boa Vista, está localizada no Município de Guamiranga, na região Sudeste do estado do Paraná e possui uma área total de $6,056 \mathrm{~km}^{2}$. Seus limites estão entre as latitudes $25^{\circ} 09^{\prime} 21^{\prime \prime} \mathrm{S}$ e $25^{\circ}$ $07^{\prime} 45^{\prime \prime} \mathrm{S}$ e entre as longitudes $50^{\circ} 54^{\prime} 44^{\prime \prime} \mathrm{W}$, e $50^{\circ} 52^{\prime}$ 25"W (Figura 1).

A bacia hidrográfica selecionada como área de estudos apresenta um predomínio de pequenas propriedades, onde $85 \%$ das áreas agrícolas são destinadas a atividade fumageira (ANTONELI e THOMAZ, 2010). O cultivo do tabaco se caracteriza como uma atividade com baixo emprego de tecnologia e com utilização de implementos e ferramentas rudimentares de tração animal o que proporciona sua expansão em pequenas propriedades com restrições ao uso.

O predomínio do cultivo do tabaco, na bacia, deve-se a alguns fatores, tais como: pequena propriedade, solos rasos com declividade média entre $8 \%$ e $25 \%$, clima subtropical com ocorrência de geadas durante o inverno, utilização de uma pequena área para o cultivo (2,5ha), rentabilidade e financiamentos da estrutura e dos equipamentos pelas empresas fumageiras, além da garantia da compra de toda a produção. Essas características contribuem para que haja um aumento nas áreas de cultivo do tabaco. Neste caso, são utilizadas áreas que indicam certas restrições de uso para o cultivo, o que pode potencializar as perdas de solo e água.

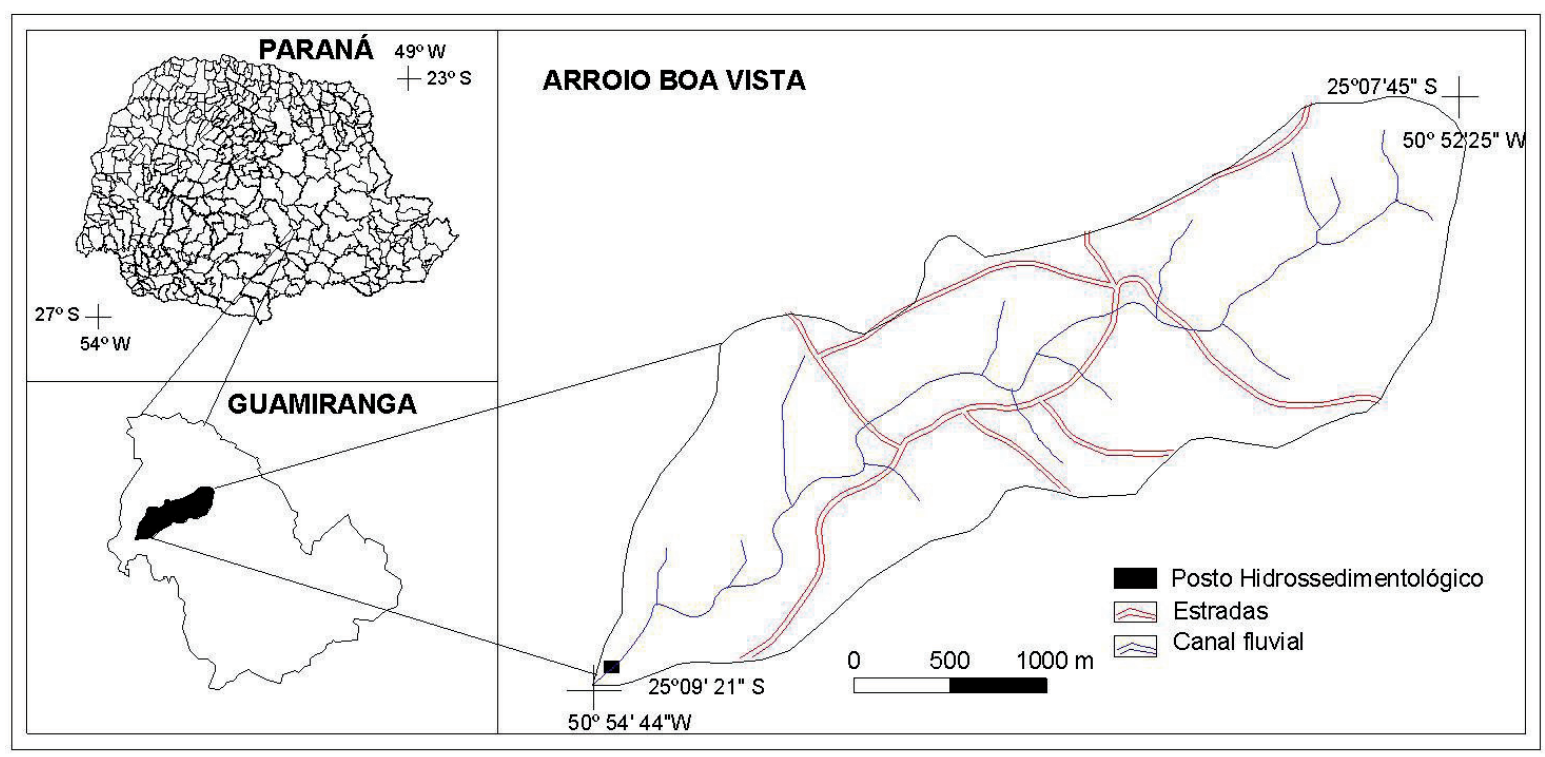

Figura 1 - Mapa de localização da bacia hidrográfica 
Segundo classificação do IAPAR (1995), a bacia se insere no conglomerado denominado $\mathrm{C} 13$, que define a região com alta participação de culturas temporárias, principalmente fumo, milho e feijão; sendo utilizada a força do trabalho familiar e de tração animal. É composta, ainda, de pastagens, mata natural de reflorestamento e áreas em pousio associadas à baixíssima utilização de insumos agroindustriais e motomecanização.

O regime climático é caracterizado segundo classificação de Köppen como Cfb, Subtropical úmido, com temperaturas médias anuais entre $17^{\circ}$ e $19^{\circ} \mathrm{C}$. A média histórica da pluviosidade (1988 a 2011) é de 2054 $\mathrm{mm}$. Deste total, $33 \%$ ocorrem na primavera, $27 \%$ no inverno, $24 \%$ no verão e $16 \%$ no inverno (ANTONELI, 2011).

No contexto regional, a área de estudo está inserida na borda oeste do Segundo Planalto Paranaense na área de transição entre os depósitos sedimentares com a Formação Serra Geral. Vale ressaltar, que no Segundo Planalto Paranaense, predominam os processos de evolução das vertentes, devido principalmente a movimentos de massa e queda de blocos nos Planaltos Residuais da Formação Serra Geral, associados a relevos de moderada/alta declividade e erosão laminar e linear associados a relevo de moderada declividade (SANTOS et al., 2007). Esta condição proporcionou na bacia do Arroio Boa Vista o surgimento de alguns diques de diábasio contribuindo para formação de Nitossolos e Argissolos (EMBRAPA, 1999).

Associados aos Nitossolos de textura argilosa existem os Argissolos que aparecem em vertentes mais longas com declividades inferiores a $10 \% \mathrm{e}$, em menor freqüência, em locais mais declivosos, principalmente, sobre o curso superior da bacia. Em áreas com declividade $>30 \%$ predominam os Neossolos que estão distribuídos em áreas de relevo ondulados a forte ondulado, sendo que nestas áreas há predomínio do cultivo do tabaco, devido a dificuldade de mecanização.

\section{Materiais e Métodos}

Para a realização desta pesquisa, utilizou-se de técnicas de mensuração dinâmica através de calhas de calhas coletoras de Gerlach, infiltrômetro manual de anel, penetrômetro de bolso e amostrador de exposição do solo.

\section{Mensuração da erosão do solo}

Para avaliação da perda de água e solo nas áreas de cultivo do tabaco, nas duas formas de cultivo, foram utilizadas parcelas com calha coletora que direcionou o fluxo de água e sedimento para um recipiente. Não foram utilizadas parcelas fechadas, pois para o plantio do tabaco é necessário construir camalhões que atuam como divisores de água direcionando o escoamento da água para um único ponto de saída no final da entrelinha onde as calhas coletoras foram instaladas (Figura 2A e 2B). Procedeu-se dessa forma, por os camalhões serem construídos de forma transversal a declividade da encosta, permitindo que as parcelas indicassem os mesmos valores de área. Essa técnica foi uma forma de adaptação das parcelas fechadas, no caso os camalhões isolam a área em que serão coletadas as amostras atuando como parcelas fechadas.

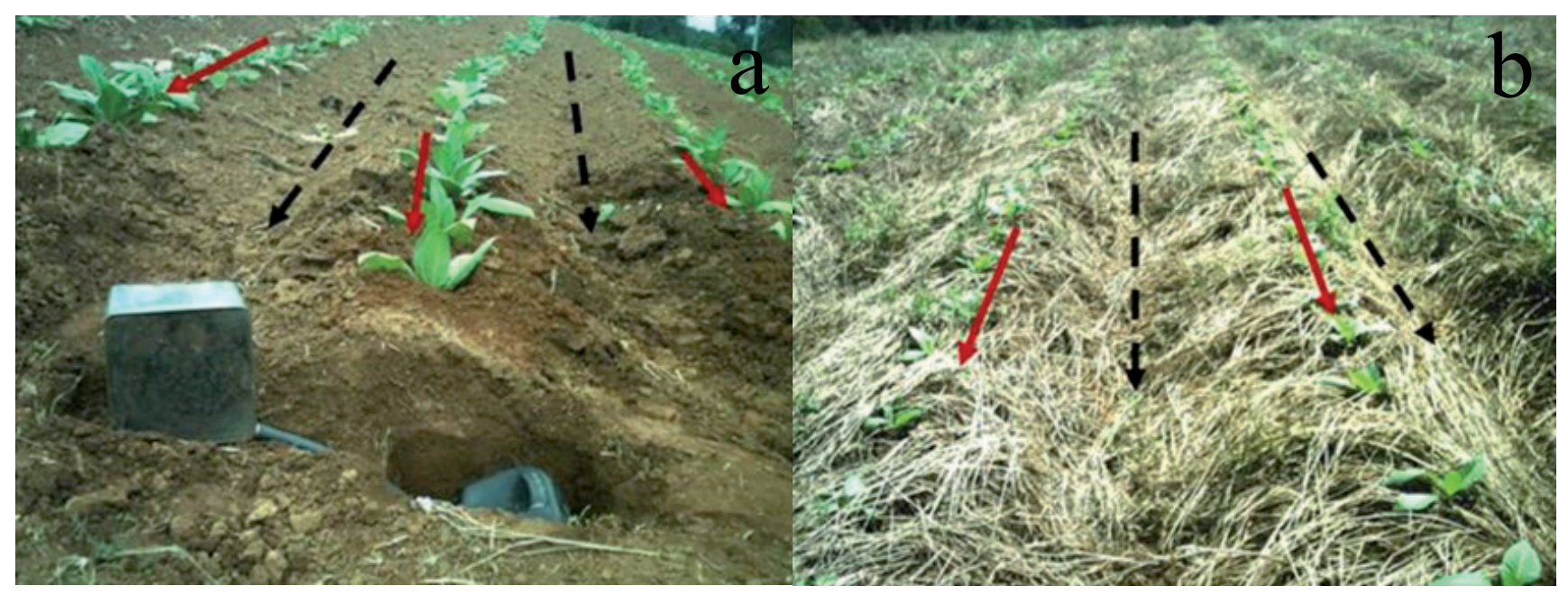

Figura 2 - a) parcela instalada em plantio convencional; b) parcela instalada em plantio direto Nota: as marcações em vermelho indicam o camalhão e as marcações em preto indicam as entrelinha. 
Cabe destacar, que nas duas formas de cultivo foram utilizados camalhões, portanto não há variação na forma de individualização das parcelas para a coleta do escoamento superficial, pois os camalhões indicam as mesmas larguras e comprimento, portanto todas as parcelas indicaram os mesmos valores de área.
Foram selecionadas duas áreas na mesma encosta, uma com Plantio Convencional e outra com Plantio Direto. Foram instaladas 7 parcelas em cada área, totalizando 14 parcelas em áreas com características semelhantes, porém com diferente forma de manejo (Tabela 1).

\section{Tabela 1: Características das duas áreas de monitoramento.}

\begin{tabular}{lcc}
\hline Características das Áreas* & Plantio Convencional & Plantio Direto \\
\hline Declividade média em \% & $12,3 \pm 1,3$ & $13,1 \pm 2,1$ \\
Comprimento das parcelas & $18,5 \pm 2,5$ & $19,5 \pm 1,4$ \\
Largura das parcelas entre os camalhões $(\mathrm{m})$ & $1,2 \pm 0,2$ & $1,1 \pm 0,4$ \\
Área de contribuição das parcelas $\left(\mathrm{m}^{2}\right)$ & $22 \pm 0,6$ & $21,5 \pm 0,4$ \\
Tipo de solo & Argissolo & Argissolo \\
Areia \% & 29,9 & 28,5 \\
Silte \% & 24,8 & 25,2 \\
Argila\% & 45,3 & 46,3 \\
pH & 5,9 & 6,1 \\
Matéria orgânica $\left(\mathrm{g} / \mathrm{kg}^{-1}\right)$ & 16,6 & 21,8 \\
\hline
\end{tabular}

*os valores de cada área, referem-se à média entre as 7 parcelas de cada área.

O monitoramento foi realizado entre os meses de setembro (início do plantio do tabaco) a março (término da colheita). Neste período foram registrados 17 eventos de chuvas que formam monitoradas através de um pluviômetro manual instalado na área.

Após cada evento, a água e sedimentos armazenados no recipiente coletor da calha, foram retirados e transferidos para outro recipiente graduado para identificar o volume escoado. Na sequência, foi homogeneizado este material por 1 minuto extraindo três amostras de $500 \mathrm{ml}$ cada, para serem enviadas ao laboratório para análise da quantidade de sedimentos em cada amostra.

Para análise da quantidade de sedimentos em cada amostra, utilizou-se o método de evaporação, no qual cada amostra foi levada estufa para evaporação a uma temperatura de $105 \mathrm{C}^{\mathrm{o}}$ por 24 horas.

\section{Avaliação da exposição do solo durante o cultivo}

Para avaliar a cobertura do solo nas duas áreas foi utilizado um amostrador de exposição de 1x1m, (Figura 3a) Este amostrador, refere-se a um quadro de madeira que foi subdividido a cada $10 \mathrm{~cm}$, formando uma malha de 100 quadros menores com $100 \mathrm{~cm}^{2}$ cada. A partir dessa malha, foi realizada a avaliação da exposição do solo em $1 \mathrm{~m}^{2}$ (ANTONELI, 2011).
Os dados foram representados em um croqui, sendo anotado o percentual de exposição de cada quadro menor $\left(100 \mathrm{~cm}^{2}\right)$. Para estimar o percentual de exposição dentro desses quadros menores, foi realizada uma avaliação visual, indicando um valor aproximado do percentual de exposição. A exposição da superfície do solo $\left(1 \mathrm{~m}^{2}\right)$ foi estimada pela equação 1 .

$$
P \exp =\frac{\sum^{n-1} q m}{N q}
$$

Onde:

Pexp $=$ Porcentagem de exposição do solo em $1 \mathrm{~m}^{2}$ $\sum^{n-1} q m=$ Somatório da exposição dos quadros menores $\left(100 \mathrm{~cm}^{2}\right)$

$N q=$ Número total de quadros menores do equipamento.

\section{Compactação do solo e infiltração de água no solo}

Para estimar a compactação na fumicultura, foi utilizado um penetrômetro de bolso (H-4200 Humboldt). A ponta da haste deste equipamento possui uma área de $0,32 \mathrm{~cm}^{2}$ e registra resistência de até $4,5 \mathrm{kgf} /$ $\mathrm{cm}^{2}$ (CARSON e KIRKBY, 1972; SELBY, 1993). As campanhas de coleta iniciaram-se em setembro (plan- 
tio), e foram realizadas mensalmente até o término da colheita (março), totalizando 7 campanhas. Foram realizadas 50 amostragens em cada campanha. As coletas foram realizadas nas entrelinhas e nos camalhões, sendo feitas 25 repetições nos camalhões e 25 repetições nas entrelinhas em cada campanha. A umidade do solo foi estimada a cada campanha através da utilização de um sensor de umidade do solo.

Para a mensuração de infiltração de água nos camalhões e nas entrelinhas do cultivo do tabaco, foi utilizado um infiltrômetro de anel simples (DUNNE e LEOPOLD,1978), (Figura 3b).

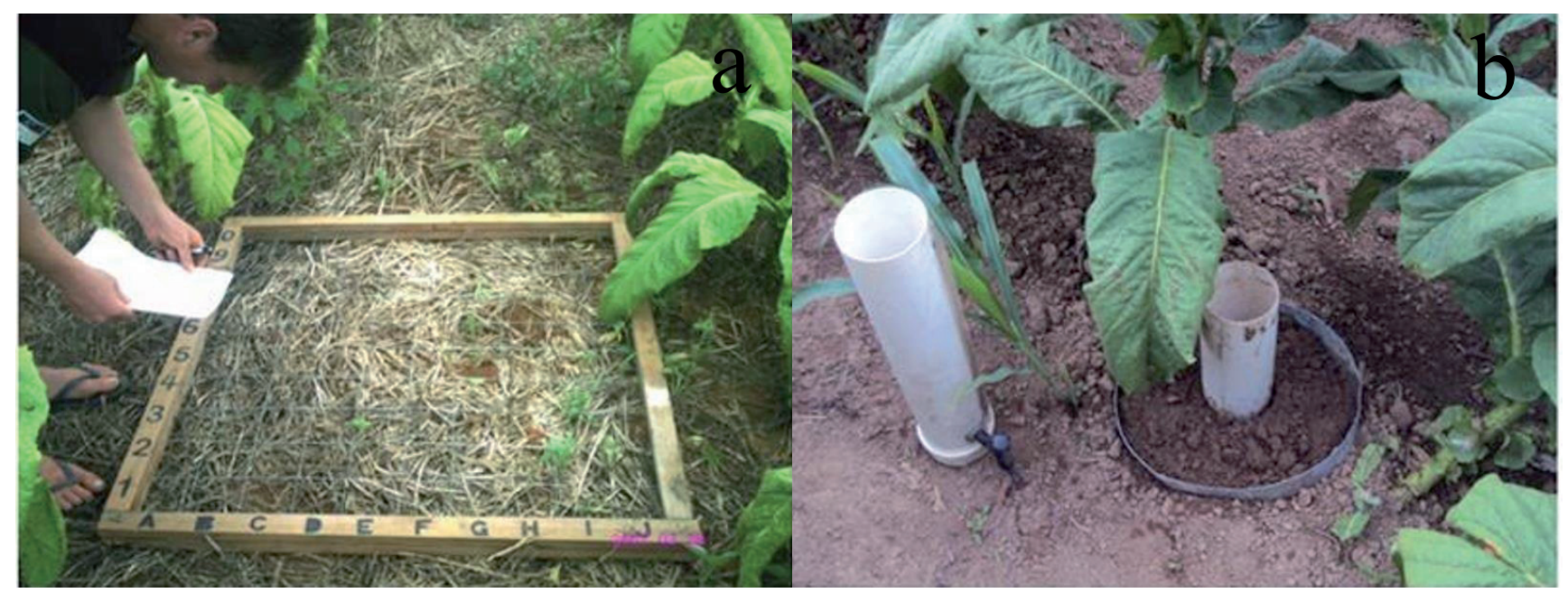

Figura 3 - a) amostrador de exposição do solo no plantio direto em área de cultivo do tabaco. b) infiltrômetro instalado no camalhão em cultivo do tabaco. Foto Antoneli, V. (2011).

Foram realizados 4 ensaios de infiltração em cada área (PC e PD) em cada campanha. Adotou-se o tempo padrão de uma hora em cada ensaio, com leitura da infiltração em intervalos de cinco minutos. A mensuração da infiltração de água no solo foi realizada mensalmente a partir do mês de setembro (plantio do tabaco) e se estendeu até março (término da colheita). Ao todo foram realizados 56 ensaios nos 7 meses de monitoramento. As coletas foram realizadas em períodos de entre chuvas.

\section{Etapas do cultivo do tabaco}

Ao longo do cultivo do tabaco há uma variação nas atividades entre as duas formas de manejo como na exposição do solo, revolvimento do solo, tráfego dos agricultores e dos animais que são utilizados para a realização das atividades, forma de limpeza para eliminação das ervas daninhas e forma de construção dos camalhões. No início da colheita, as atividades são as mesmas nas duas formas de cultivo. A variação dessas atividades foi observada mensalmente com objetivo de identificar quais as condições de campo (exposição, compactação e infiltração) que se encontra o cultivo em determinados períodos e, verificar se estas condições interferem nas perdas de água e solo.

\section{Resultados}

O cultivo do tabaco na região Sudeste do Paraná é realizado entre os meses de setembro (plantio) a março (termino da colheita). Ao longo deste período diversas atividades de cultivo são realizadas como revolvimento do solo no plantio convencional e capina de enxada para eliminar a erva daninha. No plantio direto, essas atividades não são necessárias, pois a eliminação das ervas daninhas é feita com a utilização de herbicida. As variações dessas atividades ao longo do cultivo nas duas formas de cultivo podem contribuir com respostas hidrogeomorfológicas diferentes.

\section{Dinâmica do manejo do solo em área cultivada com tabaco}

Para avaliar a perda de água e solo em cultivo de tabaco nas duas formas de cultivo foi analisada a distribuição das atividades realizadas pelos agricultores 
ao longo do cultivo nas duas formas de manejo. Disso resultou um calendário manejo do solo em área de cultivo do tabaco, (Quadro1).

As duas formas de cultivo promovem variações tanto na intensificação das atividades, quanto na exposição do solo. No início do cultivo no Plantio Direto, o solo está totalmente coberto e não há revolvimento dele nas entrelinhas e nos camalhões. Para a eliminação das ervas daninhas são utilizados herbicidas. Já no Plantio Convencional, logo após o plantio, o solo passa a ser revolvido por meio da utilização de implementos de tração animal, além da capina manual das ervas daninhas nos camalhões.

No início da colheita (dezembro), as atividades desenvolvidas nas duas formas de cultivo são iguais.
São realizadas de 8 a 10 colheitas por safras, sendo uma colheita por semana. Nestas colheitas, utiliza-se de uma caixa de madeira de $1,5 \mathrm{~m}^{3}$ que serve como recipiente para colocar as folhas que vão sendo colhidas pelos agricultores e transportadas até as estufas para a secagem. Essas caixas são transportadas através da utilização da tração animal.

Essa dinâmica de manejo da cultura resulta na variação da exposição do solo (Figura 4). No plantio direto a exposição do solo é inicialmente de $98 \%$ e atinge a maior taxa de exposição (35\%) em março. Entretanto, a taxa de exposição do solo é inferior ao verificado no plantio convencional na maior parte do período de cultivo.

\section{Quadro 1: Etapas das atividades do cultivo do tabaco nas duas formas de cultivo}

\begin{tabular}{|c|c|c|c|c|c|c|c|}
\hline \multicolumn{8}{|c|}{ Meses } \\
\hline & Set & Out & Nov & Dez & Jan & Fev & Mar \\
\hline \multirow{4}{*}{$\begin{array}{c}\text { Plantio } \\
\text { Convencional }\end{array}$} & \multicolumn{7}{|c|}{ Solo exposto - início do revolvimento com equipamentos de tração animal. } \\
\hline & & \multicolumn{6}{|c|}{$\begin{array}{l}\text { Revolvimento e construção das entrelinhas e camalhões para } \\
\text { remover as ervas daninhas - intenso tráfego do agricultor e dos } \\
\text { animais nas entrelinhas com os implementos agrícolas. }\end{array}$} \\
\hline & & & & \multicolumn{4}{|c|}{$\begin{array}{l}\text { Início da colheita - aumento da cobertura do } \\
\text { solo pela planta - aumento no tráfego. }\end{array}$} \\
\hline & & & & & & & $\begin{array}{l}\text { Término da } \\
\text { colheita. }\end{array}$ \\
\hline \multirow{4}{*}{$\begin{array}{l}\text { Plantio } \\
\text { Direto }\end{array}$} & \multicolumn{7}{|c|}{ Solo coberto pela cobertura morta - sem revolvimento } \\
\hline & & \multicolumn{6}{|c|}{$\begin{array}{l}\text { Remoção da erva daninha com herbicida - inexistência de tráfego } \\
\text { dos animais. }\end{array}$} \\
\hline & & & & \multicolumn{4}{|c|}{$\begin{array}{l}\text { Início da colheita, aumento da cobertura do } \\
\text { solo pelas plantas e redução da camada morta - } \\
\text { aumento no tráfego nas entrelinhas }\end{array}$} \\
\hline & & & & & & & $\begin{array}{l}\text { Término da } \\
\text { colheita. }\end{array}$ \\
\hline
\end{tabular}

*PC-Plantio Convencional; PD - Plantio Direto

Ao longo do cultivo, observou-se que houve uma inversão na exposição do solo. No Plantio Convencional, a exposição do solo no mês de setembro foi de $100 \%$, diminuindo à medida que as plantas do tabaco foram se desenvolvendo. No mês de fevereiro a exposição apresentou o menor valor no PC $(10,1 \%)$. No mês de março a exposição do solo apresentou um aumento devido à colheita das folhas do tabaco. Já no plantio direto, a exposição do solo no início do plantio, foi de $2,1 \%$, aumentando gradativamente ao longo do cultivo, atingindo a maior exposição no mês de março $(35,1 \%)$. Nos meses de janeiro a março a exposição do solo nas duas áreas foi muito próxima. 


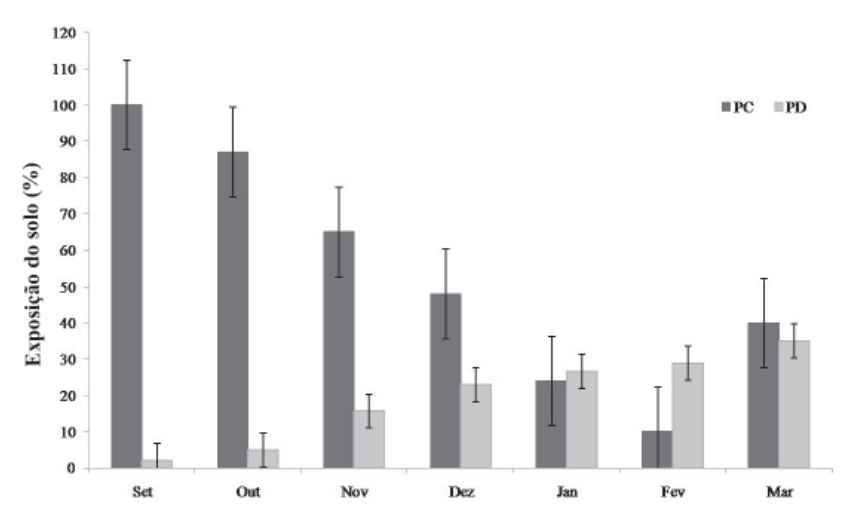

Figura 4 - Variação na exposição do solo no plantio convencional e plantio direto.

\section{Compactação e infiltração de água no solo}

Durante a colheita, (dezembro a março), as atividades se intensificaram (colheita semanal) e com isso ocorreu maior trânsito de agricultores e dos animais que são utilizados para transportar as folhas colhidas no interior da lavoura até as estufas para secagem. Esta movimentação acabou promovendo variações na compactação do solo, que contribuiu para a variação na infiltração da água. (Figura 5a e 5b).

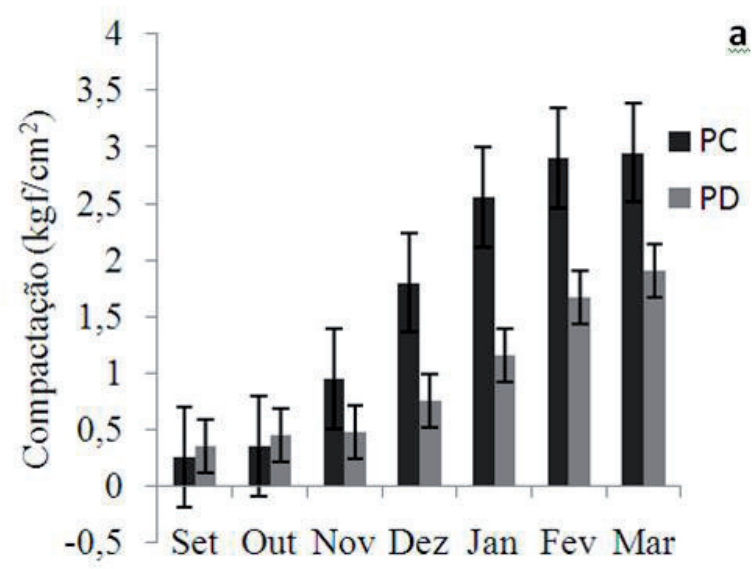

A compactação do solo no Plantio Direto e no Plantio Convencional não diferiram entre si até novembro (ambas inferiores a $1,0 \mathrm{kgf} / \mathrm{cm}^{2}$ ). No entanto a partir do mês de dezembro o Plantio Convencional apresentou um valor maior de compactação em relação ao Plantio Direto. A compactação foi aumentando ao longo dos meses nos dois sistemas de plantio. Contudo, no período da colheita o Plantio Convencional, indicou compactação do solo entre $55 \%$ a $140 \%$ superior em comparação ao Plantio Direto.

A compactação do solo influenciou na capacidade de infiltração de água no solo nos dois sistemas de plantio (Figura 5). A infiltração de água apresentou resposta inversa à compactação do solo. Assim, à medida que a compactação do solo foi aumentando a infiltração foi diminuindo gradativamente. Igualmente ao verificado com a compactação, a infiltração de água começou a se diferenciar nos dois sistemas a partir de dezembro.

Em relação à infiltração de água no solo, identificou-se que desde o início do cultivo (setembro), até novembro (término do revolvimento do solo no Plantio Convencional) os valores não diferiram estatisticamente. A partir do início da colheita (dezembro) houve uma

Figura 5 - a) compactação do topo do solo no Plantio Direto e Plantio Convencional; b) infiltração no Plantio Direto e Plantio Convencional.

redução na infiltração no Plantio Convencional enquanto que no Plantio Direto, apesar de também indicar redução na infiltração, esta redução ocorreu de forma gradativa. As médias de infiltração nas duas formas de cultivos foram de $34,8 \mathrm{~mm} / \mathrm{h}$ no Plantio Convencional e $42,1 \mathrm{~mm} / \mathrm{h}$ no Plantio Direto. No Plantio Direto a infiltração foi $20 \%$ superior à infiltração registrada no plantio convencional.

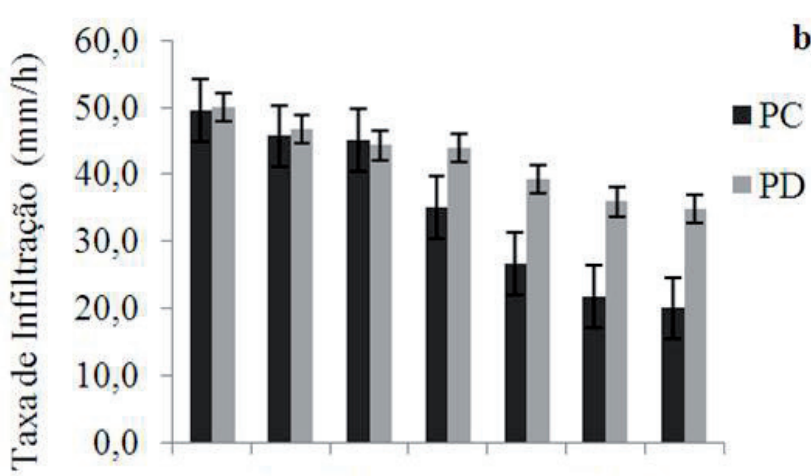

Set Out Nov Dez Jan Fev Mar

\section{$\mathrm{C}$} b 
tanto, o Plantio Convencional apresentou uma redução de $73 \%$ na taxa de infiltração no período da colheita em comparação ao Plantio Direto.

A infiltração no Plantio Convencional indicou variação menor em relação à verificada no Plantio Direto. Esse comportamento da infiltração pode indicar que o sistema convencional tende a deixar o topo do solo mais homogêneo em relação a compactação e distribuição da umidade.

\section{Perda de água e solo}

A pluviosidade do período de monitoramento foi de $1281,5 \mathrm{~mm}$, deste total, 54,1\% (694 mm) ocorreu durante o revolvimento do solo (setembro a novembro) e $45,9 \%(587,5 \mathrm{~mm})$ ocorreu durante a colheita (dezembro a março). O mês de outubro indicou maior pluviosidade (306 mm), enquanto que o mês de março indicou a menor pluviosidade (95 mm) (Figura 6).

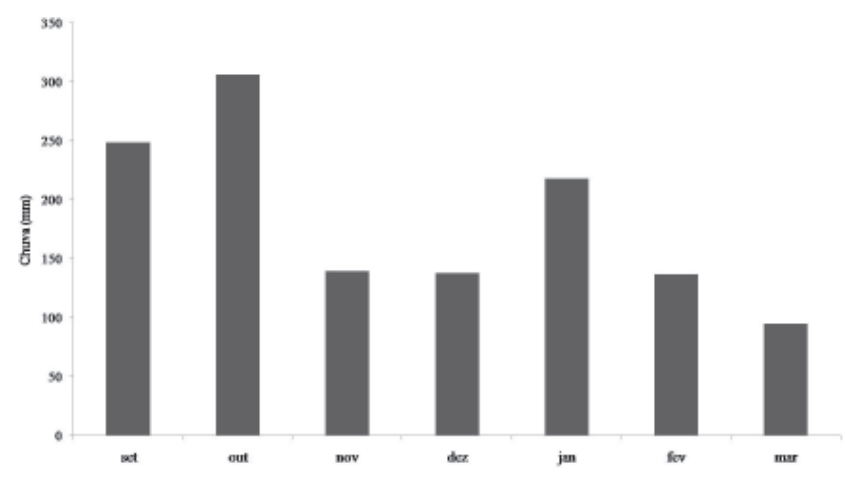

Figura 6 - distribuição da pluviosidade na área de estudo ao longo do monitoramento.

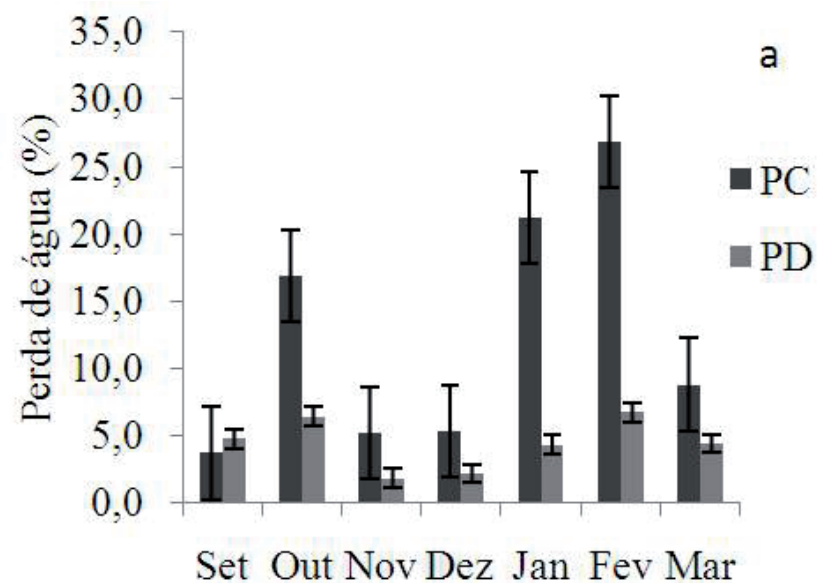

Os meses de maior pluviosidade (setembro e outubro), não indicaram influência significativa nas perdas de água e solo nas duas formas de cultivo (Figura 7a e 7b). Observou-se no início do cultivo no plantio direto que a camada morta apresentou maior índice de cobertura, reduzindo o efeito da chuva nas perdas de solo. Já no Plantio Convencional os camalhões haviam sido construídos poucos dias antes do plantio, o que pode ter aumentado a rugosidade superficial do solo, dificultando o escoamento superficial no início do cultivo.

A perda média de água durante o cultivo no Plantio Convencional foi de $12,5 \%$, variando de $3,3 \%$ em novembro a $26,8 \%$ no mês de fevereiro. Já no Plantio Direto, a perda média de água foi de $4,4 \%$, variando de $1,8 \%$ em novembro a $6,7 \%$ em fevereiro. Alguns meses indicaram picos de perda de água (janeiro e fevereiro, ambos acima de $15 \%$ ), o restante dos meses apresentaram perdas inferiores a $10 \%$ no Plantio Convencional. Em contrapartida no Plantio Direto, a perda de água indicou pouca variação, mesmo nos meses de maior volume de precipitação. Durante a safra o plantio direto registrou perda de água duas vezes inferior às registradas no plantio convencional. Esse menor escoamento superficial influenciou na perda de solo.

A perda de solo no Plantio Convencional foi de $4,18 \mathrm{~kg} / \mathrm{m}^{2}$, variando entre $0,08 \mathrm{~kg} / \mathrm{m}^{2}$, no mês de setembro a $1,34 \mathrm{~kg} / \mathrm{m}^{2}$, no mês de fevereiro. Já no Plantio Direto, a perda total foi de $0,71\left(\mathrm{~kg} / \mathrm{m}^{2}\right)$, variando entre $0,05 \mathrm{~kg} / \mathrm{m}^{2}$, no mês de outubro a $0,16 \mathrm{~kg} / \mathrm{m}^{2}$, em fevereiro. O Plantio Direto indicou redução de 5,8 vezes a perda de solo em comparação ao Plantio Convencional. Apenas no início da safra (setembro) as perdas de solo

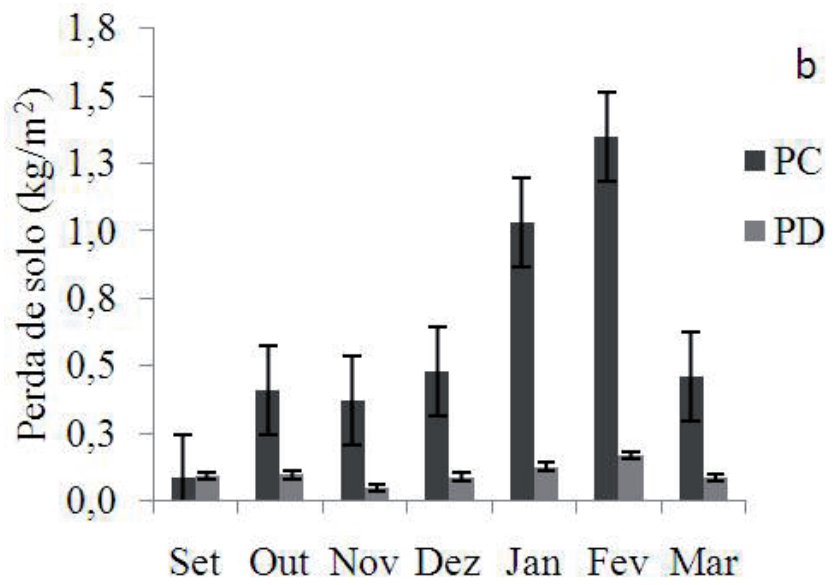

Figura 7 - a) Perda de água no Plantio Direto e Plantio Convencional; b) perda de solo no Plantio Direto e Plantio Convencional. 
nos dois tipos de manejo foram equivalentes. Quando extrapolados os dados de perda de solo, estima-se uma perda de 41,8 t/ha no Plantio Convencional e uma perda de 7,1 t/ha no Plantio Direto. Cabe destacar, que estes valores são referentes ao período do cultivo (setembro a março).

\section{Discussão}

As perdas de solo nas áreas de cultivo de tabaco dependem da forma de manejo e das atividades desenvolvidas ao longo do cultivo. Neste contexto, não basta apenas mensurar a perda de solo nas áreas é necessário investigar a dinâmica de cada forma de cultivo, pois cada uma propicia variações distintas no manejo.

\section{Dinâmica do manejo do solo e influências na exposi- ção do solo, compactação e infiltração de água}

O cultivo do tabaco por ser uma atividade temporária, mas de recorrência anual, promove alterações constantes no manejo do solo da área de estudos. Essa dinâmica no manejo se reflete nas respostas hidrogeomorfológicas das vertentes ocupadas com a cultura do tabaco potencializando as perdas de solo e, por conseguinte um aumento no material que chega até os corpos hídricos. Antoneli e Thomaz (2010) vêm corroborar com esta questão ao observarem que a produção de sedimentos total em cabeceiras de drenagem em área de cultivo de tabaco foi 3 vezes superior no período da safra em relação à entresafra.

Entre os meses de abril a agosto, os solos das áreas cultivadas com tabaco permanecem com cobertura vegetal de inverno geralmente aveia preta (Avena strigosa). A cobertura do solo nesta fase contribui para a redução dos processos erosivos. Contudo, entre os meses de setembro a março há uma intensificação do uso do solo por causa das atividades desenvolvidas ao longo das etapas do cultivo o que acaba contribuindo para a variação da exposição do solo, potencializando os processos erosivos. Esta variação depende da forma de cultivo, pois no plantio convencional, o solo fica exposto, além se ser revolvido constantemente desde o plantio (setembro) até o início da colheita (dezembro). Foi observado nesta pesquisa que houve uma variação significativa na exposição do solo no plantio convencional, o que pode ter contribuído com as perdas de água e solo.
No plantio direto, a exposição do solo foi menor ao longo do cultivo, no entanto, as atividades diárias e a decomposição da cobertura morta foram potencializando a exposição do solo ao longo do cultivo. Entretanto, durante todo o período de cultivo, a cobertura do solo não ficou abaixo de $35 \%$. Apesar da redução da cobertura, observa-se na literatura que esta incide na variação da infiltração da água no solo e na perda de água e solo (PANACHUKI et al., 2011).

No plantio convencional, as atividades são mais intensas havendo várias repetições de atividades, como a capina e o revolvimento do solo para a remoção da erva daninha. Desta forma, o solo acaba compactando devido ao pisoteio. No plantio direto o trânsito do agricultor e dos animais durante o cultivo é reduzido por algumas atividades não serem necessárias como a capina e o revolvimento do solo. No entanto, as atividades realizadas durante a colheita (dezembro a março) são iguais em ambas as formas de cultivo. Essas atividades implicaram no aumento da compactação do solo nas duas formas de cultivo, pois a utilização de equipamentos agrícolas durante a colheita assim com em outras operações ao longo do cultivo resulta no aumento da compactação do solo (LARA DE ASSIS e LANÇAS, 2005; HAMZA e ANDERSON, 2005; LAGACHERIE et al., 2006).

O aumento de compactação em ambas as formas de cultivo com o inicio da colheita, influenciaram na infiltração de água no solo. No plantio direto, a infiltração se manteve superior ao plantio convencional por esta forma de cultivo reduzir o efeito da chuva na formação de crostas superficiais devido a cobertura morta, bem como na redução da velocidade do escoamento superficial (STONE e SILVEIRA, 1999).

Durante o revolvimento do solo no plantio convencional (setembro a novembro), a infiltração foi maior. Este comportamento está associado à menor compactação da camada superficial. Na medida em que houve redução do revolvimento do solo (dezembro a março), a infiltração no plantio convencional passou a reduzir.

A taxa de infiltração de água no solo estimada foi $20 \%$ superior no plantio direto em comparação ao plantio convencional. Valor próximo daquele estimado por Truman et al. (2003) que verificaram em parcelas com plantio direto variação de $11 \%$ a $49 \%$ superior ao Plantio Convencional

Observou-se que a infiltração da água no solo no plantio convencional sofreu influência do revolvimento 
do solo concordando com resultados obtidos por Colodro (2005) e Alves et al. (2007). Enquanto que no plantio direto, a mecanização (revolvimento) do solo promove inicialmente o aumento da infiltração, contudo com o passar do tempo essa condição vai se deteriorando indicando redução na infiltração (BRANDÃO et al., 2009; SATO et al., 2012).

\section{Influência do cultivo de tabaco na perda de solo}

Em caminhamento pela área de estudo ao longo do monitoramento observou-se que a estrutura e a morfologia da planta do tabaco contribuíram para a perda de água e solo, por estas atuarem como concentradores e canalizadores de água. O comprimento das folhas variam do tabaco variam entre 15-35 centímetros e de 5-20 centímetros de largura (SILVA e MENTZ, 2005), possuem formato ovaladas, elípticas ou lanceoladas com pecíolo curto e alado. Acredita-se que essas características de estrutura e morfologia da planta potencializam a interceptação da água da chuva direcionando a água interceptada para a entrelinha. Assim, o maior fluxo direcionado para a entrelinha pode ter aumentado a taxa de salpico, escoamento difuso e posteriormente o escoamento concentrado (Figura 8).

A influência das folhas no escoamento superficial e na erosão está mais relacionada com o estádio vegetativo da cultura do que pelo sistema de plantio direto ou convencional (ENGEL et al., 2009). Em alguns casos, o efeito da cobertura do dossel pode provocar o aumento do salpico. Plantas do tipo couve-de-bruxelas com cobertura de $50 \%$ produz salpicamento equivalente a um solo sem proteção (NOBLE et al., 1983). As folhas dessa planta (couve-de-bruxelas) possuem alguma similaridade com as folhas de tabaco. Portanto, estas características podem ter influenciado na perda de solo nas duas formas de cultivo, especialmente, no plantio convencional. Contudo, a forma de manejo nas duas áreas foi preponderante como principal fator na perda de água e solo.

Outro elemento que contribui para o processo erosivo é a forma dos camalhão. O camalhão fornece material salpicado que devido à morfologia do terreno após a construção dos mesmos direciona este material para a entrelinha que concentra o escoamento promovendo maior escoamento. Bryan e Rockwell (1998) relatam que alguns estudos mostram que a taxa de erosão do solo aumenta com o início dos sulcos. A capacidade de transporte de sedimentos nas entrelinhas é incrementada com o aumento da declividade da área (MEYER et al., 1975). No caso dos camalhões, estes já são construídos em desnível para escoamento da água, contribuindo para a formação do fluxo. (Figura 9).

Após a construção dos camalhões foi observado maior rugosidade superficial devido a torrões que se desprenderam dos camalhões e algumas micro depressões que se formaram na entrelinha contribuindo para a redução do escoamento superficial nos inicio do monitoramento. Quando se iniciam as atividades de cultivo do tabaco, principalmente com o revolvimento do solo,

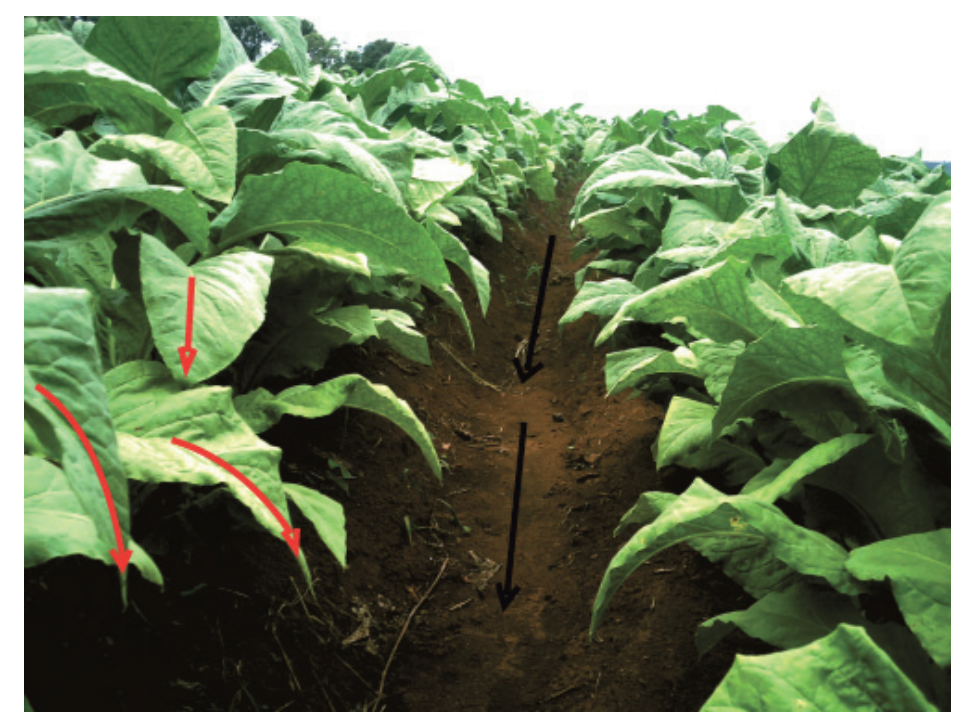

Figura 8 - Característica das folhas do tabaco

Nota: As setas vermelhas exibidas nas folhas de tabaco indicam a captura da água da chuva e as setas sólidas indicam solo exposto e a direção do escoamento superficial entre as linhas de tabaco. 
esses obstáculos vão sendo reduzidos contribuindo assim para a concentração do escoamento superficial nas entrelinhas.

Neste estudo, foi observado que a perda de água no Plantio Convencional foi 3 vezes maior em relação ao Plantio Direto, valor próximo daqueles estimados por Langdale et al. (1979), que estimaram perdas de água 2 vezes maior no plantio convencional. Já a perda de solo no plantio convencional foi 5,8 vezes maior em relação ao plantio direto, valor próximo daqueles encontrados na literatura em outros cultivares (Tabela 2). Apesar de os dados da literatura provirem de culturas, bem como condições edafoclimáticas distintas entende-se que os resultados desta pesquisa são consistentes com os verificados na literatura.

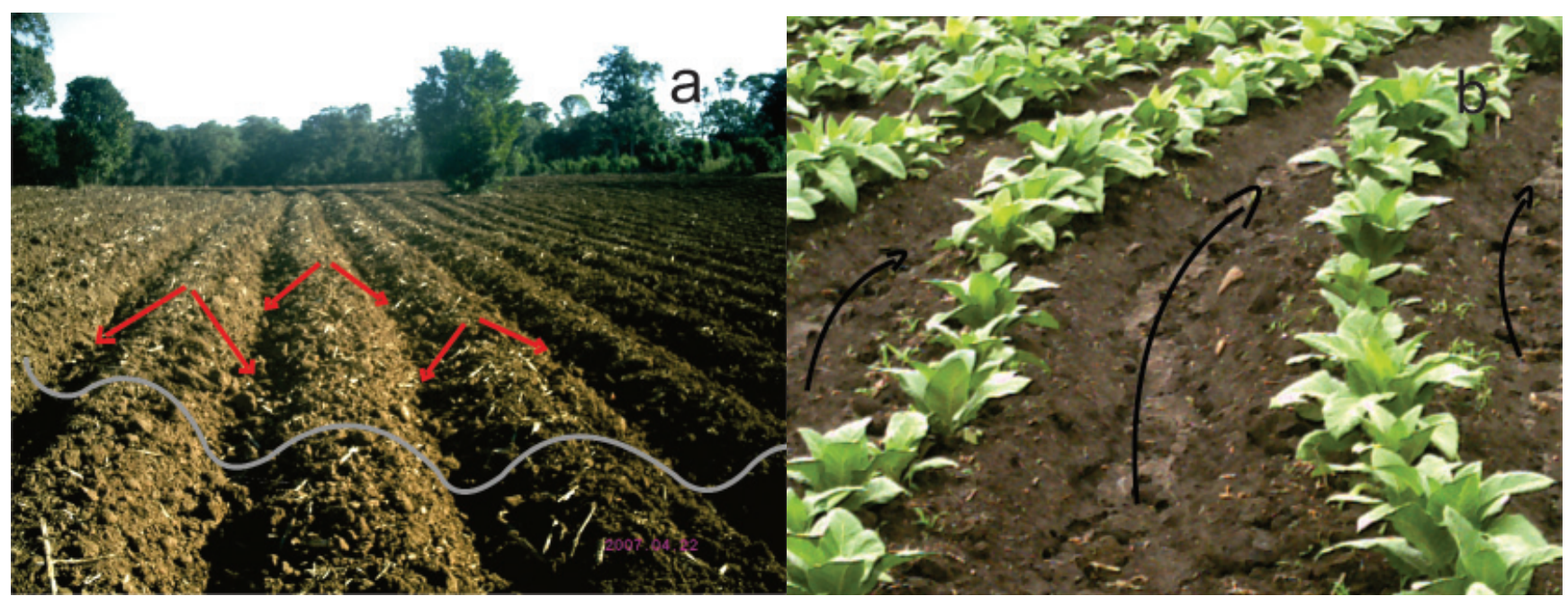

Figura 9 - Morfologia dos camalhões. a) formato dos camalhões antes do plantio do tabaco onde a linha em preto indica a morfologia do camalhão e as marcações em vermelho indicam a declividade e direção da água para o centro das entrelinhas; b) fluxo na entrelinha durante a chuva.

Tabela 2: Variação de perda de solo entre Plantio Convencional e Plantio Direto em cultivo de tabaco.

\begin{tabular}{|l|l|l|l|}
\hline Fonte & Cultivares & $\begin{array}{l}\text { Variação de perda de } \\
\text { solo entre PC e PD. }\end{array}$ & Localização \\
\hline Delaune \& Sij (2012) & Trigo & 3 a 10 vezes maiores & Texas-USA \\
\hline Leite et al. (2004) & Milho e feijão & 9 vezes & Santa Catarina - BR \\
\hline Truman et al. (2003) & Algodão & 1,5 a 5,4 vezes & Alabama - USA \\
\hline Pugliesi et al. (2011) & Mamona & 14 vezes & São Paulo - BR \\
\hline $\begin{array}{l}\text { Wood \& Worsham } \\
(1986)\end{array}$ & Tabaco & 20 vezes & $\begin{array}{l}\text { Carolina do Norte } \\
\text {-USA }\end{array}$ \\
\hline
\end{tabular}

Por meio da tabela 2, observa-se a importância da adoção de práticas conservacionistas nas áreas agricultáveis. Pesquisas relacionadas à adoção do Plantio Direto vem sendo desenvolvidas por mais de meio século em muitos países ao redor do mundo, principalmente por razões econômicas, para reduzir o consumo de energia e de trabalho e melhorar os resultados ambientais. A utilização do Plantio Direto é uma importante estratégia para reduzir a erosão do solo e do escoamento da água em áreas agrícolas (SCHULLER et al., 2007; DELAUNE, 2012) e quando se trata do cultivo do tabaco, a utilização desta forma de manejo torna-se imprescindível, tendo em vista os valores das perdas de solo encontrados.

A utilização deste sistema vem auxiliar na produtividade (JEMAI et al., 2013), melhorando as condições do solo, no entanto esta técnica é pouco aplicada no cultivo do tabaco, por diversas questões, tais como; áreas com restrições ao uso, pequenas propriedades e 
falta de informações a respeito da importância de efetuar o cultivo com plantio direto.

\section{Conclusão}

Ao término desta pesquisa foi possível concluir que o manejo do solo é um fator determinante na perda de água e solo no cultivo do tabaco, no entanto a ação conjunta das outras variáveis também contribui para essas perdas, havendo uma relação multicausal entre as variáveis. No caso do plantio convencional, desde o plantio até a colheita há maior exposição do solo devido ao constante revolvimento, influenciando na redução da compactação e aumento na infiltração da água. Com o inicio da colheita e a intensificação das atividades, observou-se que a compactação foi aumento e a infiltração foi diminuindo, potencializando as perdas de água e solo

No plantio direto, a camada morta foi perdendo sua eficiência ao longo do cultivo, principalmente durante a colheita (dezembro a março) onde há um trânsito constante nas entrelinhas dos agricultores e dos animais que são utilizados para a realização das atividades na lavoura. Já no plantio convencional mesmo com o aumento da cobertura do dossel pela própria planta do tabaco não houve redução nas perdas de água e solo. A morfologia da planta pode ter contribuído para o aumento de perdas de solo por direcionar parte da água para a entrelinha.

Nos primeiros meses de cultivo a infiltração e compactação do solo não diferiram entre si. Contudo, com o aumento da exposição do solo no plantio direto e término do revolvimento do solo no plantio convencional a compactação do topo do solo foi aumentando e a taxa de infiltração foi diminuindo. A infiltração média de água no solo no plantio direto ao longo do cultivo do tabaco foi $20,9 \%$ superior ao plantio convencional. Já a compactação do solo foi $78,4 \%$ superior no plantio convencional.

Mesmo o cultivo do tabaco sendo realizada em áreas com certas restrições a mecanização, há a necessidade de que nessas áreas o cultivo seja efetuado na forma de plantio direto sobre cobertura morta. A mecanização com tração animal não é um impedimento para essa prática, pois podem ser construídos os camalhões com equipamentos de tração animal e adicionar cobertura vegetal.

\section{Referências}

ALVES, M. C.; SUZUKI, L. G. A. S.; SUZUKI, L. F. A. S. Densidade do solo e infiltração de água como indicadores da qualidade física de um Latossolo Vermelho Distrófico em recuperação. Revista Brasileira de Ciência do Solo, v. 31, n,1, p. $617-625,2007$.

ANTONELI, V.; THOMAZ. E. L. Relação entre o cultivo de fumo (nicotina tabacum) e a produção de sedimentos na Bacia do Arroio Boa Vista, Guamiranga - PR. Revista Geografia Rio Claro-SP. v. 35, n 2, p. 383-398. 2010.

ANTONELI, V. Dinâmica do uso da terra e a produção de sedimentos em diferentes áreas fontes na bacia hidrográfica do Arroio Boa Vista- Guamiranga-PR. Tese de Doutorado em Geografia pela Universidade Federal do Paraná - UFPR. Curitiba, 2011. 354p.

BARTON, A. P.; FULLEN, M.A.; MITCHELL, D.J.; HOCKING, T.J.; LIU, L. WU BO, Z.; ZHENG, Y.; YUAN XIA, Z. Effects of soil conservation measures on erosion rates and crop productivity on subtropical Ultisols in Yunnan Province, China. Agriculture, Ecosystems \& Environment. v.104, n. 2, p. 343-35. 2004.

BRANDÃO, V. S.; PRUSKI, F. P.; SILVA, D. D. Infiltração da água no solo. 3.ed. Viçosa: UFV, 2009. 120p.

BRYAN, R.B. e ROCKWELL, D.L. Water table control on rill and implications for erosional response. Geomorphology. v.23, n.1, p.151-169. 1998.

BAKKER, M. M.; GOVERS,G.; KOSMAS, C.; OOST, V. V. K. VAN.; ROUNSEVELL, M. Soil erosion as a driver of landuse change. Agriculture, Ecosystems \& Environment. v.105, n.3, p. 467-481. 2005.

CARSON, M.A. e KIRKBY, M.J. Hillslope form and process. Cambridge: Cambridge University Press, 1972. 476p.

COLODRO, G. Recuperação de solo de área de empréstimo com lodo de esgoto. Tese Doutorado. Universidade Estadual de Campinas, Campinas, 2005. 82p.

DELAUNE P.B.; SIJ, J.W. Impact of tillage on runoff in long term no-till wheat systems. Soil \& Tillage Research v.124, p. 32-35, 2012.

DUNNE, T, LEOPOLD L. Water environmental planning. San Francisco. Freeman e Company, 1978. 818p.

EMPRESA BRASILEIRA DE PESQUISA AGROPECUÁRIA - EMBRAPA. Sistema Brasileiro de Classificação de Solos. Rio de Janeiro: Embrapa Solos, 2009. 412p. 
ENGEL, F, L.; BERTOL, I.; RITTER, S.R.; PAZ GONZÁLEZ, A.; PAZ-FERREIRO, J.; VIDAL VÁZQUEZ, E. Soil erosion under simulated rainfall in relation to phenological stages of soybeans and tillage methods in Lages, SC, Brazil. Soil and Tillage Research. v.103, n.2, p. 216-226, 2009.

HAMZA, M.A.; ANDERSON, W.K. Soil compaction in cropping systems. Soil and Tillage Research. v.82, n. 2, p.121$145,2005$.

IAPAR - Instituto Agronômico do Paraná. Caracterização da Agricultura no Paraná. Londrina, 1995. 87 p

JEMAI, I; AISSA, N. B.; GUIRAT, S. B.;BEN-HAMMOUDA, M.; GALLALI, T. Impact of three and seven years of no-tillage on the soil water storage, in the plant root zone, under a dry subhumid Tunisian climate. Soil and Tillage Research. v.126, p.26-33, 2013.

LARA DE ASSIS, R. e LANÇAS, K. P. Avaliação dos atributos físicos de um Nitossolo Vermelho distroférrico sob sistema plantio direto, preparo convencional e mata nativa. Revista Brasileira de Ciência do Solo. v.29, p.515-522, 2005.

LAL, R. Tillage effects on soil degradation, soil resilience, soil quality, and sustainability. Soil and Tillage Research. v. 27, n. 1-4, p. 1-8. 1993.

LANGDALE, G.W.; BARNETT, A.P.; LEONARD, R.A.; FLEMING, W.G. Reduction of soil erosion by the no-till system in the Southern Piedmont. Transactions of the ASAE, v. 22 n.1, p.82-86, 1979.

LAGACHERIE, P.; COULOUMA P. G.; ARIAGNO, P.; VIRAT, P.; BOIZARD, H. RICHARD, G. Spatial variability of soil compaction over a vineyard region in relation with soils and cultivation operations. Geoderma. v.134, n.1-2, p. 207- 216, 2006.

LEITE, D.; BERTOL, I.; GUADAGNIN, J. C.; SANTOS, E. J.; RITTER, S. R. Erosão hídrica em um Nitossolo Háplico submetido a diferentes sistemas de manejo sob chuva simulada. I - perdas de solo e água. Revista Brasileira de Ciência do Solo. v.28, p, 1033-1044, 2004.

MEYER, L.D.; FOSTER, G. R.; RÔMKENS, M.J.M. Source of soil eroded by water from pland slopes. In: ESTADOS UNIDOS. Department of Agriculture Research Service. Present and prospective technology for predicting sediment yieldes and sources. Washington. v.1, p.177-189. 1975.

MERTEN, G.H.; MINELLA, J.P.G. Impact on sediment yield due to the intensification of tobacco production in a catchment in Southern Brazil. Ciência rural. Santa Maria. v.36, n.2, p.
669-672. 2006.

NOBLE, C. A., \& MORGAN, R. P. C. Rainfall interception and splash detachment with a Brussels sprouts plant: a laboratory simulation. Earth Surface Processes and Landforms, v.8, n.6, p. 569-577. 1983.

OWENS, L.B.; MALONE, R.W.; HOTHEM D.L.; STARR, G.C.; LAL, R. Sediment carbon concentration and transport from small watersheds under various conservation tillage practices. Soil \& Tillage Research. v. 67, p.65-73, 2002.

PANACHUKI, E.; BERTOL, I.; SOBRINHO, T. A.; OLIVEIRA, P. T. S. de; RODRIGUES, D. B. B. Perdas de solo e de água e infiltração de água em latossolo vermelho sob sistemas de manejo. Revista Brasileira de Ciência do Solo. v. 35, p.1777$1785,2011$.

PELLEGRINI, A. Sistemas de cultivo da cultura do fumo com ênfase às práticas de manejo e conservação do solo. Dissertação de Mestrado. Universidade Federal de Santa Maria. 2006. 91p

PUGLIESI, A. C. V; MARINHO, M. A; MARQUES, J. F; LUCARELLI, J. R. F. Valoração econômica do efeito da erosão em sistemas de manejo do solo empregando o método custo de reposição. Bragantia. v.70, n. 01, p.113-121, 2011.

SANTOS, L.J.C. OKA-FIORI, C., CANALLI, E.N.; PIO FIORI, A. SILVEIRA, C. T. DA.; SILVA J. M. F. da. Mapeamento da Vulnerabilidade Geoambiental do Estado do Paraná. Revista Brasileira de Geociências. v, 37, n. 4, p. 812-820, 2007.

SATO; J. H.; FIGUEIREDO, C. C. DE; LEÃO, T. P.; RAMOS, M. L. G.; KATO, E. Matéria orgânica e infiltração da água em solo sob consórcio milho e forrageiras. Revista Brasileira de Engenharia Agricola e Ambiental. v.16, n.2, p.189-193, 2012.

SELBY, M. J. Hillslope materials and processes. Oxford: Oxford University Press, 1993. 451 p.

SILVA, M. V.; MENTZ, L. A. O gênero Nicotiana L. (Solanaceae) no Rio Grande do Sul, Brasil. IHERINGIA, Série. Botânica. Porto Alegre, v. 60, n. 2, p. 151-173, 2005.

SLATTERY, M. C.; BURT, T. P.; GARES, P. A. Dramatic Erosion of a Tobacco Field at Vanceboro, North Carolina. Southeastern Geographer v.37, n.1, p.85-90, 1997.

STONE, L. F.; SILVEIRA P. M. da. Efeitos do sistema de preparo na compactação do solo, disponibilidade hídrica e comportamento do feijoeiro. Pesquisa agropecuária Brasileira. Brasília, v.34, n.1, p.83-91,1999.

SCHUller, P.; WALling, D.E.; SEPÚlVEDA, A.; 
CASTILlO, A. \& PINO, I. Changes in soil erosion associated with the shift from conventional tillage to a no-tillage system, documented using ${ }^{137} \mathrm{Cs}$ measurements. Soil \& Tillage Research, v.94 n.193-192, 2007.

TRUMAN, C.C., REEVES, D.W.; SHAW, J.N.; MOTTA, A.C.; BURMESTER, C.H.; RAPER, R.L.; SCHWAB, E.B.; Tillage impacts on soil property, runoff, and soil loss variations from a Rhodic Paleudult under simulated rainfall. J. Soil Water Conservation. v. 1 n.58, p.258-267, 2003.

WOOD, S. D.; WORSHAM, A. D. Reducing soil erosion in tobacco fields with no-tillage transplanting Journal of Soil and Water Conservation v.41, n.3, p.193-196, 1986. 